\title{
Parents' Challenges of Home-Schooling Children with Autism Spectrum Disorder: A Special Journey
}

\author{
Maria Cecilia M. Fadare ${ }^{\# 1}$, Bituin B. Carrera ${ }^{\# 2}$, Stephen A. Fadare ${ }^{\# 3,}$ Daniel B. Paguia ${ }^{\# 4}$ \\ ${ }^{1,2,4}$ Saint Louis College, City of San Fernando, La Union, Philippines \\ ${ }^{3}$ College of Sport Physical Education and Recreation, Mindanao State University (Main) Marawi, Philippines.
}

\begin{abstract}
This phenomenological research analysed the experiences, challenges, and coping mechanisms of parents in the home schooling of children with autism spectrum disorder in the City of San Fernando La Union. The participants were eight (8) parents with children clinically diagnosed with autism spectrum disorder during the School Year 2020-2021. The data gathered using a semi-structured interview guide was thematically analysed. It was found that the participants were fully involved in the home-schooling of their children. Difficulties in the area of rules and authority, schedules and procedures, behaviour management, and parental worry and stress were the challenges encountered by the parents during the home education process. They addressed these transitional difficulties by capitalizing on a positive disposition, gaining support from family members, and through professional consultation. It was concluded that a renewed Parent-School Partnership is deemed necessary for the learning continuity of children with ASD. Based on these findings, the researchers have developed a thematic model which can be used as a guide to enhance home-schooling. In addition, a colloquium scheme as a support program was crafted to up skill parents' home-schooling of children with ASD.
\end{abstract}

Keywords - COVID-19, Hermeneutic Phenomenology, Parents of Children with ASD, Parent-School Partnership, Special Education

\section{Introduction}

Education plays an important role in the development of a country. If a country does not have proper education, it may be left behind by other countries which support education. There are many factors that affect the education system. Culture, technology and economic matters give much impact to the education system of a country. The regulation made by the government affects how the education system works in a country. Education is essential in human's life. And as time goes by, system of education changes dynamically following the needs of human beings.

The world suddenly underwent a major and abrupt change with the advent of COVID-19, a virus outbreak that was termed as a pandemic by the World Health Organization in March 2020 (WHO, 2020). The impact of COVID-19 is evident with schools and colleges shifting classes online and work from home becoming a way of life throughout the globe. Commonly termed as social distancing or social isolation, has led to a lack of daily routine and structure. Maintaining a routine induces a sense of discipline as well as safety in children, which is important for their psychological and emotional development (Narzisi, 2020).

With schools being suspended nationwide in 189 countries since April 2020 (UNICEF, 2020), the entire education system has shifted online. While online classes are proving to be favourable for most students, not much is talk about its impact for children with disabilities. The education of students with profound intellectual and multiple disabilities presents diverse challenges to teachers and families. Teaching students with Profound Intellectual and Multiple Disabilities (PMID) is considered to be difficult because these students often find learning more challenging than others (Imray et al., 2010).Making adjustments on routines, like, experiencing closure of schools and day care centers, social distancing and/or confinement to home can prove to be a real struggle for children with physical and mental disabilities (Bartlett et al., 2020). The handling of children with special needs such as autism spectrum disorder(ASD) could be challenging for families, caregivers and teachers, 
DOI: $\underline{10.51386 / 25815946 / \mathrm{ijsms}-\mathrm{v} 4 \mathrm{i} 4 \mathrm{p} 102}$

Volume: 4 Issue: 4

July to August 2021

https://www.ijjsmsjournal.org

thus needing a more careful care and guidance to avoid an increase parental stress and exacerbation of children's behavioural problems.

Caring for a child with a developmental disability has been known to contribute to higher levels of stress than caring for a child with typical development (Ingersoll \& Hambrick, 2011). The birth of a child with a disability causes stress in the family, most especially among parents, which consequently affects the quality of life of the parents. It is more challenging for parents to take care of children with disabilities, like those children diagnosed with ASD, than for parents of normal or ordinary children. Given that chronic stress can have negative effects on a range of physical as well as psychosocial wellbeing (Ludlow et al., 2012), the parents of children with ASD have also been found to have poorer health and more illnesses than parents of normal or ordinary children (Bonis, 2016).

In the Philippines, disability is one of the social issues affecting a portion of the Philippines' population. The Philippine government passed laws and policies concerning persons with disabilities (PWDs) under RA 7277 An Act Providing for the Rehabilitation, Self-Development, and Self-Reliance of Disabled People, and Their Integration into the Mainstream of Society and Other Purposes - in order to ensure disabled people's equality and rights (NCDA, 2020).

Under the implementation of the Republic Act 7277 (Magna Carta for Disabled Persons) and to achieve the target set for the Asian and Pacific Decade of Disabled Persons (1993-2002) that 75\% of the 4 million children with disabilities should be provided equal educational opportunities, special needs education shall be institutionalized in all schools. Institutionalization means the provision of access to basic education for children with special needs, namely, the gifted/talented, the mentally retarded, the visually impaired, the orthopedically handicapped, the learning disabled, speech defectives, children with behavior problems, children with autism and those with health problems, through the formal system and other alternative delivery services in education.

With the outbreak of the corona virus, the worldwide pandemic has brought many disruptions on many countries, which has resulted in school closure and had left countless parents scrambling as they take on new home-schooling responsibilities (Klein, 2020). School closures present several risks for children's learning, especially those from the marginalized and disadvantaged communities, particularly those children living in poverty, children from remote and ethno-linguistic communities and those children with disabilities. This will greatly impact on their academic progression and achievement.

During the COVID - 19 pandemic, the Department of Education (DepEd) implemented "adaptive learning methods for learners" and received support from Save the Children Philippines, a group that promotes children's rights and welfare. It is a non-negotiable fundamental human right. Children should have continued access to education, even in times of emergencies such as the COVID-19 pandemic," a former Undersecretary of DepEd, said, "But we must put in place children's safety, which is paramount, and make sure that they have a safe and inclusive learning environment" (Alcober, 2020).

Educators, such as teachers, parents, and guardians, have the capacity and sufficient support to deliver effective new learning methods that must be gender-sensitive and inclusive. They should integrate psychosocial and socio-emotional support for learners during the pandemic at home using other delivery modes depending on the local COVID Risk Severity Classification and compliance with minimum health standards (Capulso, 2020). Learning delivery options such as blended learning and distance learning have been adopted in both public and private schools. Transitioning to teaching your kids at home during coronavirus school closures can be challenging for many families.

\section{LITERATURE REVIEW}

\section{a. Experiences of Parents with Children in the Autism Spectrum}

Research shows that parents of children with ASD experience more stress than other parents. Both formal and informal supports are important for these parents to obtain. Formal supports include supports provided by an agency and can include family doctors, early intervention programs, and respite care providers. Families use 
DOI: $\underline{10.51386 / 25815946 / \mathrm{ijsms}-\mathrm{v} 4 \mathrm{i} 4 \mathrm{p} 102}$

Volume: 4 Issue: 4

July to August 2021

https://www.ijjsmsjournal.org

formal supports for information and professional guidance. Informal supports refer to support provided by someone in the person's social network such as friends, family, neighbors, or acquaintances.

Eshraghi et al., (2020) explained that elevated parenting stress has been observed among mothers of children with ASD in western countries. By examining maternal parenting stress in Heilongjiang province of China, it has been observed that Chinese mothers of children with ASD experience stress. The reports by parents in China put more emphasis on parenting stress. Mothers' parenting stress was associated with levels of depression and anxiety, and child's behavioral symptoms. Child's behavioral symptoms, maternal anxiety, maternal depressive symptoms, and lack of governmental financial support were associated with overall parenting stress.

Some studies have investigated the level of stress in parents and guardians of children with ASD; one major aspect of stress is stigmatization. Stress levels in parents of children with autism have been shown to be higher than those in other parents (Hastings et al., 2015).

According to a literature review of a study by Eshraghi et al., (2020) on identifying supports for parents of children with ASD, she cited a study by Clifford \& Minnes (2013), parents who have a child with ASD participated in a parent support group to see if parental well-being would increase following participation in a support group. The parents in this study were asked to rate their experience with the support group. It was found out that the parents enjoyed participating and found the support group to be very valuable and helpful, recommending it to other parents.

\section{b. Challenges in Parenting Children with ASD}

Falk et al. (2014) conducted a study on the stress experienced by parents of children with ASD.In this study, they sent out a questionnaire to parents who had a child with ASD. The findings suggest that parents of children with ASD struggle to understand their child's behaviors. Furthermore, he emphasized that when parents do not see positive changes in their child's behavior, they start to feel ineffective as parents.

Although there is research that indicates that parenting a child with ASD is very stressful, there is still little research on the specific challenges that parents face. It is imperative to understand the specific challenges parents of children with ASD face, and how they perceive the situation. Most programs designed for children with ASD focus mainly on the child's outcomes rather than on their parental needs. Most of the time, the content of the programs is determined by what professionals believe parents need to know, rather than identifying their wishes (Samadi et al., 2012).

\section{c. Coping Mechanisms of Parents}

Parents of children with ASD use a range of coping strategies and resources when faced with parenting/caregiving stress (Lai \& Oei, 2014). In a review paper, Lai and Oei, (2014) highlighted that parent of children with ASD use both adaptive (e.g., cognitive reframing; seeking social support) and maladaptive (e.g., avoidance and disengagement) coping strategies, with an inclination towards adaptive coping methods such as seeking social support and positive reinterpretation. Among parents of children with ASD, the use of adaptive coping strategies has also been linked to positive mental health outcomes (Benson, 2010). While it may be expected that parents of children with ASD adapt well to parenting stress, past studies have also consistently reported elevated stress symptoms in these parents (Hayes \& Watson 2012). It is therefore unclear if parents of children with ASD are coping with parenting/caregiving stress adequately and effectively (Hayes \& Watson 2012). Moreover, some studies have suggested more frequent use of maladaptive coping strategies among parents of children with ASD than parents of children with non-ASD developmental disabilities or those with typical development (Eshraghi et al., 2020).

In general, the nature of parenting stress and coping among parents of children with ASD, especially when compared to parents of children not diagnosed with this disorder, remains inconclusive (Lai \& Oei 2014). Currently, there is a paucity of research on parental wellbeing and coping among Asian parents of children with ASD residing in Asian countries (Lai \& Oei 2014; Moh \& Magiati 2012). Previously, Asia-based studies have either one (1) reported differences in parenting/caretaking experiences by comparing parents of children with ASD residing in different countries (e.g., Yeo \& Lu, 2012) or two (2) examined parents' overall experience of 
DOI: $\underline{10.51386 / 25815946 / \mathrm{ijsms}-\mathrm{v} 4 \mathrm{i} 4 \mathrm{p} 102}$

Volume: 4 Issue: 4

July to August 2021

https://www.ijjsmsjournal.org

the diagnostic process for their child (e.g., Moh \& Magiati, 2012). While having their merits, comparisons across different countries overlook the differences in parenting culture, environment and expectations that are inherent in the population, which can alter the impact of raising a child with ASD (Lai \& Oei 2014).

Findings on stress and coping research in parents of children with ASD and existing cultural differences between Asian- and Western-based studies render any direct application of Western literature to Asian populations limited. (1) It is hypothesized that parents of autistic children will report more parenting stress, depression, and anxiety symptoms than parents of typically developing children. Since ASD-related behaviors can impact parenting stress to varying degrees (Eshraghi et al., 2020), the current study also sought to understand parenting stress, and parent-reported depression and anxiety symptoms based on the diagnosis of the child (i.e., compared between parents of children with Autism, Asperger's Syndrome, PDD-NOS and with typical development), as an elaboration of Hypothesis (1). Practically, this categorization of parental experiences could also be valuable in assisting clinicians to tune in quickly to the needs of specific parent populations based on the child's reported diagnosis (Eshraghi et al., 2020).

\section{d. Family-School Partnership}

When parents and professionals partner with one another to meet the needs of individuals with ASD, it can have a positive impact on the quality of their cognitive, social, and emotional development (Whitbread et al. 2017). Specifically, Whitbread et al. (2017) found that successful parent-professional partnerships can produce better outcomes for individuals.

Parental involvement in the education of students begins at home, with parents providing a safe and healthy environment, appropriate learning experiences, support, and a positive attitude about school. Several studies indicate increased academic achievement among students that have involved parents (Epstein, 2010). By examining parents' and teachers' perceptions, educators and parents should have a better understanding of effective parental involvement practices in promoting student achievement.

Numerous researchers, such as Berger (2015) and Epstein (2010), have studied parental involvement and its effects on the educational process over the years. A leading researcher into parental involvement is Joyce Epstein, the founder and director of the National Network of Partnership Schools at Johns Hopkins University. With numerous studies and work in over 100 publications, Epstein focuses on school, family, and community partnership programs that will improve policy and practice in an effort to increase student academic achievement and student success. Epstein has identified a framework which contains six important factors with regards to parental involvement. These six factors are parenting, communication, volunteering, at-home learning, decision-making, and community collaboration. Parenting includes all of the activities that parents engage in to raise happy, healthy children who become capable students (Perras, 2021). Unlike teachers, whose influence on a child is relatively limited, parents maintain a life-long commitment to their children.

The second factor identified by Epstein is communication. It is described thatfamilies and schools communicate with each other in multiple ways. Schools send home notes and flyers about important events and activities. Parents give teachers information about their child's health and educational history. A school website is an additional mode of communication with parents and families. Modes of communication and exchanging information include conferences with every parent at least once a year, language translators to assist families as needed, a regular schedule of useful notices, memos, phone calls, newsletters, and other forms of communication available. The factor of volunteering applies to recruiting and organizing help and support from parents for school programs and students' activities. Individuals volunteer in three basic ways for education. First, they may volunteer in the school or classroom by helping teachers and administrators as tutors or assistants. Second, they may volunteer for the school, for instance, by fundraising for an event or by promoting the school in the community.

Parental involvement plays an important role in learning at home as it pertains to providing ideas and information to parents about how they can best assist their children with homework and curriculum-related decisions and activities. Parents helping their children with homework and monitoring the continuity of their Individual Education Program (IEP) at home are examples of this type of involvement. These activities produce 
DOI: $\underline{10.51386 / 25815946 / \mathrm{ijsms}-\mathrm{v} 4 \mathrm{i} 4 \mathrm{p} 102}$

a school-oriented family and encourage parents to interact with the school curriculum. Activities to encourage learning at home provide parents with information on what children are doing in the classroom and how to help them with homework. In order to provide an appropriate education for ASD children, parents of children with autism need specialized knowledge, skills, and scientifically based information about autism and its treatment. Among these are mastery of specific teaching strategies that allow them to assist their children in learning new behaviors, as well as an understanding of the nature of autism and how it influences their children's learning patterns and behavior. All children and young adults require support from caregivers during times of stress and uncertainty, such as the corona virus (COVID-19).

The aforementioned literature has helped researchers understand that ASD is a major issue not only in the Philippines, but also in Asia and around the world. Looking at the statement of Borromeo (2014), in the Philippines, estimated cases of autism doubled in number from half a million in 2008 to one million in 2014. At this point, it was anticipated that this figure would be much higher. Also, considering Asia as a whole, according to a study by Sun \& Allison, (2010), the overall reported prevalence of ASD in recent studies is higher than previously reported in Asia. Therefore, extrapolations from this literature on the challenges of parenting children diagnosed with ASD were found to be relevant to this study.

The researchers believe that the best method to articulate this study is the use of interpretive phenomenological design, as this method studies the individual's life as experienced. The researchers are more convinced of continuing this study in the hope that assisting parents in overcoming the challenges that come with raising a child with ASD will invariably benefit ASD children as well.

The purpose of this study was to gain a thorough understanding of parents' experiences, challenges, and coping mechanisms when teaching their children with ASD at home in the midst of a global health pandemic (covid-19 crisis).

\section{III.METHODOLOGY AND METHODS}

This study used phenomenological research to examine parents' experiences, challenges, and coping mechanisms when homeschooling their children with ASD. The participants were eight (8) parents with children clinically diagnosed with ASD. The data collected were subjected to thematic analysis using a semi-structured interview guide. This research used the phenomenological approach to qualitative research, particularly hermeneutics or interpretive phenomenological design. The participants were purposefully selected as key informants in the study because they are the ones who have the first-hand experience of determining the challenges and coping strategies for the homeschooling of their children with ASD. The primary data gathering is conducted through an interview guide as a basis for the discussion through a face-to-face interview following safety health protocols.

\section{FINDINS AND DISCUSSION}

\section{Thematic Model for Homeschooling Children with ASD}

The analysis of the transcribed responses of the participants, done through intelligent transcription, revealed the participation, challenges and coping mechanisms experienced by parents of homeschooling children with ASD. The theme classified under the participation of parents/caregivers in home schooling children is Parental/Guardian Involvement. For the challenges of parents/caregivers of homeschooling children, the theme was Unwrapping Transitional Difficulties. The theme for the coping mechanisms of parents was Parent-School Partnership and what made parents/guardian involvement in their child's home schooling a special journey was Essential Learning Designs.

The researchers formulated the thematic model for homeschooling children with ASD based on the gen erated themes from the responses of the participants and the significant findings of the study. 


\section{DOI: $10.51386 / 25815946 / \mathrm{ijsms}-\mathrm{v} 4 \mathrm{i} 4 \mathrm{p} 102$}

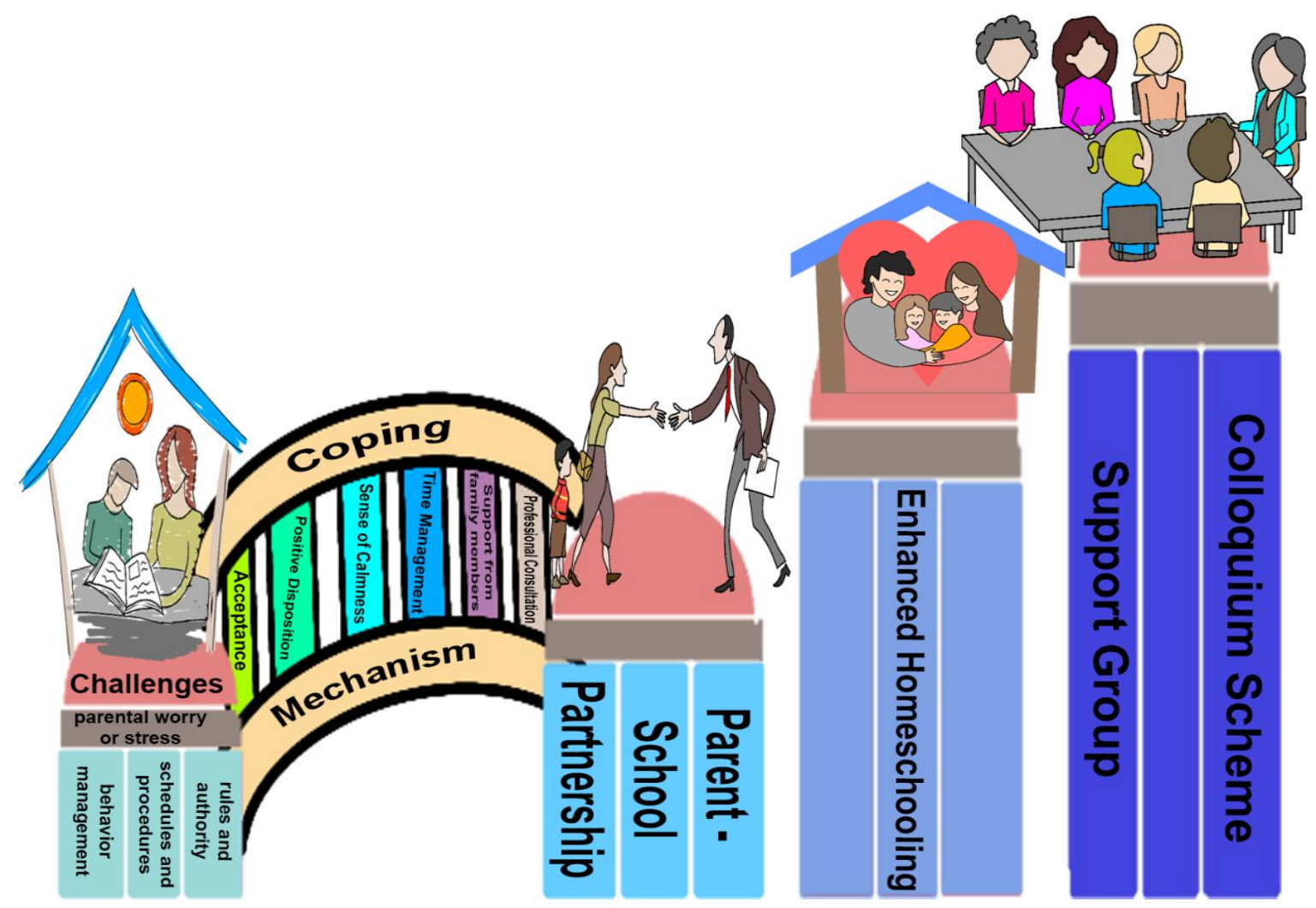

Figure 1: Thematic Model for Homeschooling Children with ASD

The model utilizes symbols that represent the lived experiences of the parents/guardians of children with autism spectrum disorder in home schooling - their involvement and challenges relative to the learning process of their children at home, and coping mechanisms adopted to survive the home education process. The model epitomizes the very nature of the current study on parents' challenges of home-schooling children with autism spectrum disorder.

This model is intended to inform parents about the home education process that occurs during school closures. This will steer their way towards achieving more support, growth and development to navigate this special journey. The first figure on the left side shows a mother teaching her child in a home setting. This "new normal" in education has shifted to a new role and responsibility for parents to teach their children at home. This novel role has presented parents of children with ASD with a variety of challenges as they transition from school to home education. Transitional challenges include rules and authorities, schedules and procedures, and behavior management, all of which cause parental concern and stress. The next image shows an overpass. This represents the various coping mechanisms employed by parents in order to crossover and maneuver through these challenges encountered in homeschooling. Coping mechanisms start with acceptance. Recognizing and accepting their new role as teachers for their children during school closures increases parental involvement in home education. Viewing things and situations from a different perspective is a way of having a positive disposition in life. The parents exhibited a sense of calmness and the pursuit of their dreams and goals for their children, gave them strength and motivation, therefore increasing their ability to cope with the stressful situation.

One way of managing homeschooling, as this study revealed, is by having good time management. Parents have learned to manage their time effectively. They were able to balance work, personal time, family time, and 
DOI: $\underline{10.51386 / 25815946 / \mathrm{ijsms}-\mathrm{v} 4 \mathrm{i} 4 \mathrm{p} 102}$

Volume: 4 Issue: 4

July to August 2021

https://www.ijjsmsjournal.org

homeschooling their children. The support they gained from other members of the family alleviated their struggles and made them empowered to perform and function to the best of their ability.

In the quest to cope with the current situation of homeschooling their children, parents have adopted a method of consulting and connecting with the teachers in school and special therapists. The Parent-School Partnership was renewed. The teachers and the school, together with the parents, are equally vital in making homeschooling effective for children with ASD. Effective and consistent teacher-parent communication based on mutual trust and respect creates a partnership that will ensure the child with ASD develops to his full potential.

Parents working in collaboration with the school and the community to make the home education process of children with ASD fruitful and rewarding comprise the fourth figure. This is the result of the unity between the parents and the school coming together and the process of teamwork to shape and mould the uniqueness of children with ASD.

The last image shows the proposed support group for the parents of children with ASD and the colloquium scheme that should be adopted and implemented by the schools. The colloquium's goal is to provide parents with information and awareness about how to home educate their children with ASD.This also gives parents a better understanding of the types of support and potential interventions that they may require. Lastly, the colloquium will help develop an effective parent-school partnership to achieve positive educational outcomes specifically for children with ASD at this time of the pandemic crisis.

The researchers present four major themes with sub-themes:

\section{Involvement of Parents/Guardians in Home Schooling}

Parents are typically the primary caregivers for their children and play an important role in their children's learning and development, making them an essential link between the home and school environments, particularly in the "new normal" education process.

The COVID-19 pandemic has led the government to impose various restrictive measures to prevent its wider spread. For parents and children, staying at home while studying is one of these measures. By DepEd Order (DO) No. 012, s. 2020, "Adoption of the Basic Education Learning Continuity Plan (BE-LCP) for the school year 2020-2021 in the light of the COVID-19 Public Health Emergency," DepEd shall employ multiple learning delivery modalities (LDMs) to ensure the continued provision of learning opportunities to its learners while protecting the health and safety of both its personnel and learners. This can be done through blended learning, distance learning, and homeschooling. These modifications to certain policies and practices were necessary steps in adapting to the "new normal" while still remaining true to the framework of Sulong Edukalidad and Education Futures. This is in support of what Education Secretary Leonor Briones emphasized that parents are in charge of their children's studies in the homeschooling setup.

Children with special needs are particularly vulnerable to losing access to an education as a result of contagion containment measures. As such, efforts to improve home education methods for children with special needs are being exerted in the hope of assisting parents as they educate their children with special needs while safely staying at home. Therefore, parental involvement is crucial in children's home education with special needs, particularly autism spectrum disorder.

\section{Parental/Guardian Involvement}

The DepEd Order No. 32, 2020 demands for a holistic approach and a stronger partnership among schools, households, and communities. Parents who read to their children, assist with their homework, and provide tutoring using resources provided by teachers tend to do better in school than children whose parents do not assist them. Parents must understand their importance on the success of the process of education and on the upbringing of their children. It is important for parents to be aware of the impact of the pandemic on children's academic performance and wellbeing. 
DOI: $\underline{10.51386 / 25815946 / \mathrm{ijsms}-\mathrm{v} 4 \mathrm{i} 4 \mathrm{p} 102}$

Volume: 4 Issue: 4

July to August 2021

https://www.ijjsmsjournal.org

When asked, "How did you participate in your child's home schooling?" They take pride in revealing their involvement in home educating their children and how they are doing better than their children's teachers. For instance, Parent A shared, "I, as a parent, was the one who taught my child about his modules, I am happy to assist him in doing his activities."Parent $\mathbf{C}$ confirms that, "I am the one who is in charge of assisting my son during his online class, and I follow up with his modules."In a similar manner, Parent $\mathbf{E}$ proudly stated that, "I am the prime parent working and assisting my kid with his module."Parent B shared that, "I am the one who gives the schedule and tasks at home and the modules."Parent D highlighted that" Our grandchild has always been our primary concern, as we are happy to teach him at home."

Furthermore, Shourbagi (2017) stressed the importance of parents and caregivers' involvement in the home schooling of their children, as their participation in teaching their children has been linked to increased parental confidence in, and satisfaction with, parenting, as well as increased interest in their own education. This, in turn, prepares them to be ideal teachers and caregivers for their children. Parents are the most significant people in the lives of children, particularly children with special needs. They provide the basic needs of the family and children, as in Maslow's hierarchy of needs, which also includes the physiological needs of safety and security. Their full participation and involvement in their children's home education is confirmation that their time spent with children causes them (parents and children) to thrive and blossom into a sense of belonging and being loved. Over and above all the medical, psychological, and scientific means of treating them, children with special needs respond most to the warmth of love, caring and patience. Parents are the only adults in the educational process who have been and will continue to be deeply involved throughout the child's school career, and while they may not be educators themselves, they bring their years of experience in other professions and aspects of life to the process.

\section{Challenges of Parents/Caregivers in Home Schooling Children with ASD}

Many families face unique challenges when it comes to educating and assisting their children during homeschooling. It may be difficult to consider the role of parents in raising a child to the level of attending school, but Kidd (2010) found that parents, particularly mothers, have the ability to provide their children with an education that is suited to the way in which they learn. She further discussed that mothers also have the ability to control their child's environment in order to enable learning to take place.

\section{Unwrapping Transitional Difficulties}

The disruptions caused by the health crisis cause significant changes in the routines of children with autism. The transition from studying in a four-walled classroom to confinement in their own homes, with their parents acting as both the teacher and a classmate, is a significant change in the children's daily school routine. Transitional difficulties in the area of rules and authority, schedules and procedures, behavior management, and parental worry and stress fall under this domain. The application of rules and routines helps them engage more successfully in activities and prevents problem behavior. As a result, imposing rules and exercising authority can be difficult for parents because their children are already accustomed to attending school with the teacher exercising authority and enforcing rules during the learning process. The children's association with their teachers in school as educators was broken and interrupted during the transition. Thus, reinforcement is inconceivable, specifically in the scheduling of activities and implementation of procedures, which eventually poses another struggle in homeschooling children with ASD. These were emphasized by Parent A when she states that, "It was difficult for him to adjust at first because he got used to having a teacher."Parent B added,"It is a struggle because he does not want to write."Parent $\mathbf{C}$ adds, "The challenges that I encountered would bein getting him ready for class. "Meanwhile, Parent $\mathbf{F}$ responded, "When the time for the online class needs to be adjusted for important reasons, he tends to be sleepy and not participative."Parent E, "I cannot really explain how he will answer it, so I just write down notes on the module that my son cannot answer at this level. My son is unable to respond to these questions. "Parent $\mathbf{F}, "$ The module is too general. In their cases, having ASD, they have different learning curves."

The transition from school to home can be upsetting for the child, resulting in an emotional meltdown if the routine is disrupted by unexpected changes and people. The National Autistic Society (2021) described a 
DOI: $\underline{10.51386 / 25815946 / \mathrm{ijsms}-\mathrm{v} 4 \mathrm{i} 4 \mathrm{p} 102}$

Volume: 4 Issue: 4

July to August 2021

https://www.ijjsmsjournal.org

meltdown as an intense response to an overwhelming situation. It happens when someone becomes completely overwhelmed by their current situation and temporarily loses control of their behavior. This loss of control can be expressed verbally (shouting, screaming, crying), physically (kicking, lashing out, biting) or in both ways. Meltdowns are not the only way that a child with ASD may express their feelings of being overwhelmed. They may also refuse to interact, withdrawing from situations they find challenging or avoiding them altogether.

A child with ASD will show signs of distress before having a meltdown, which is sometimes referred to as the "rumble stage". They may start to exhibit signs of anxiety, such as pacing, seeking reassurance through repetitive questioning or physical signs such as rocking or becoming very still. This is manifested when Parent F says,"So, once you change the schedule, his behavior changes as well. He won't be able to fully participate in his class. Task avoidance. He gives numerous reasons." Behaviors of children with ASD as mentioned by Parent C, "making sure he is in a good mood and had a good night sleep," and supported by the statement of Parent D, "We can only start our lessons and modules at home when my child is in the right mood. 'The parents were trying to anticipate a meltdown or a change in the child's behavior. The child's undesirable behavior and emotional meltdown will give rise to parents' stress and worry. In addition, when Parent $\mathbf{H}$ underscored one of the difficulties he encountered," It is difficult at first because he is already used to go to school so I need to explain why he is studying here at home. It is difficult because it's been months since schools were closed, so he has had a regression. For example, those sounds he was previously familiar with, he could no longer identify," showed that the worry of regression on the part of the child causes significant stress on parents. When a child appears to develop typically but suddenly begins to lose speech and social skills, the condition is called regressive autism.

Parenting stress refers to the perceived stress of the parent in reaction to the demands of parenting the child, and Fadare et al (2021) suggest that the child's difficult behaviors contribute to the parent's negative mood via decreases in parenting self-efficacy. Since mothers of children with ASD experience higher levels of stress compared to mothers of typical children, their increases in parenting stress may reduce parenting self-efficacy, which in turn might lead to increases in anxiety and depression.

\section{Coping Mechanisms of Parents}

School closures have led to the emergence of online classes and modular learning as a "new normal" in the learning continuity of students. In this situation, parents are now rearing and educating children while simultaneously attending to their respective jobs and employment. Others have lost their jobs, do not have jobs or are trying to find jobs during these trying times. With these everyday struggles, parents have learned to cope and adapt to this "new normal" and it has brought them opportunities for learning and growth. In this study, parents' coping mechanisms include acceptance, positive disposition, a sense of calmness, time management, support coming from other family members, and, lastly, professional consultation.

\section{Acceptance}

According to the APA Dictionary of Psychology (2021), acceptance is a favorable attitude toward an idea, situation, person, or group. Acceptance occurs when a situation or scenario is acknowledged and accepted by an individual. It is typically used in reference to an acknowledgement of and assent to a negative situation. Parents embracing their new role can be seen in Parent G's statement, "You have no choice but to accept the responsibility to teach your child, to assist him with his homeschooling." This was supported by the statement of Parent F, "You have no choice. You have to go online. You have to really prepare yourself as a parent. You really have to attend. Sit with him. "Learn alongside him."

Parents pointed out that their new responsibility during this "new normal" of education left them with no choice but to accept and acknowledge this current role of being teachers to their children at home. Preparing themselves and attending to their child's learning through sitting and learning with the child manifests their acceptance of the concept of homeschooling. Research shows that acceptance is an important trait of positive well-being. 
DOI: $\underline{10.51386 / 25815946 / \mathrm{ijsms}-\mathrm{v} 4 \mathrm{i} 4 \mathrm{p} 102}$

Volume: 4 Issue: 4

July to August 2021

https://www.ijjsmsjournal.org

\section{Positive Disposition}

Having a positive disposition means having an optimistic outlook and attitude towards life despite experiencing adversity. The parents were faced with the challenge of having multifaceted roles, including homeschooling their children, and they looked at it from a different perspective when Parent $\mathbf{C}$ stressed that,"I remind myself that it is okay if the schedule does not go to plan every day. Every day is an opportunity to fine tune what is working and eliminate what is not working." And Parent $\mathbf{B}$ answered, "We, the parents, will have a closer relationship with our child because we see to it that we spend more time with our child."Parents reassure themselves that they are doing their best at home, educating their children and focusing on what they can do and accomplish at a specific time, which teaches them how to let go of what they cannot accomplish at a given time. They look at something positive and focus on that.

Moreover, positivity also touches on self-talk. For example, Parent $\mathbf{C}$ responded, "I am keeping it calm. I remind myself that it is okay if the schedule does not go as planned. 'The ability to cope with stressful situations improves as a result of this parents' positive attitude toward remaining calm. The more you practice positive self-talk, the more automatic positivity will become in your life. A positive disposition could further mean moving forward towards your dreams and goals in life. As Parent $\mathbf{E}$ divulged, "I have to work well to educate him the best that I can. I should have to prepare him for his life the moment we are no longer here." Parent $\mathbf{F}$ supported this by saying, "You want to see your child be normal, and so you hope for him to become normal, although the chances are slim, but at least with the education he is getting, the therapy he is getting, he is learning everyday things. And that is what is important."

In the midst of the homeschooling challenges, parents have tried to figure out how to become positive, stay calm and move forward. Being a parent of a child with ASD presents many challenges, but it is how they rise to overcome these challenges with strength and positivity that is important.

\section{Time Management}

For parents wrestling with the demands of everyday life, time management proves to be a real struggle. The additional responsibility of home educating a child with ASD who has unique and special needs can be a huge task that requires a significant amount of time for parenting. According to the article "What is Time Management?" (2021), time management is the process of organizing and planning how to divide your time among specific activities. It discusses how good time management allows you to work smarter and accomplish more in less time, even when time is limited and pressure is high. Failing to manage your time damages your effectiveness and causes stress. Parenting is hard work, and learning and keeping in control of their time makes their personal life and family life run smoothly. Parents strengthened this characteristic as Parent C shared, "I tried setting a schedule as this would make him feel excited." This was validated by Parent B when she answered, "By setting a schedule to follow, we think that it is for his improvement."'Parent $\mathbf{H}$ also approved this by saying, "We have a schedule, like we are going to study at a specific time." As Parent $\mathbf{C}$ concludes, "Teaching him after my work during night time. We exercise on the weekend."

Parnell (2017) pointed out that having good time management in homeschooling will give parents total and complete control over their child's environment, education and social experiences. This will also allow the child to avoid and minimize sensory triggers, as children with ASD thrive on routine and structure. Time management and structuring activities that work for the family's schedule will help the child and other family members do their best with the learning plan provided by the school while being safe in the confinement of their homes. More importantly, time management enables parents to increase their family time and gives them the opportunity to spend more time watching their children grow and learn. In reality, homeschooling jobs for parents are more about creating safety, belonging, and acceptance than they are about academics.

\section{Support from Family Members}

The "new normal" in education has shifted toward parents homeschooling their children, which necessitates a significant amount of time. This also calls for help and assistance from other members of the family. It is of 
DOI: $\underline{10.51386 / 25815946 / \mathrm{ijsms}-\mathrm{v} 4 \mathrm{i} 4 \mathrm{p} 102}$

Volume: 4 Issue: 4

July to August 2021

https://www.ijjsmsjournal.org

importance to gain support and assistance throughout the home education process. Getting support from your family gives you time for other things that need to be accomplished and empowers you to be able to navigate the challenges of family life. Parent D confirmed this when responding, "We help each other together with the grandmother to attend to his needs because we are the only ones who can understand him and his situation."'Parent $\mathbf{E}$ added, "What we do is the brother or the father will get the module then we schedule a certain time during the week to do the module."

In the midst of the continuing global pandemic which greatly impacted many lives, including business, education, and economic stability a strong support system coming from your own family is significant to your holistic wellness. For parents who are taking a much more active role in the education of their children, their wellness together with other family members is vitally important, as all people perform and function best when they are well and empowered.

The coping mechanisms exhibited by parents correlate with the Family Stress Theory, which is described as the resiliency model of family stress, adjustment, and adaptation. The main emphasis of this model is on the resiliency of families and their ability to recover from the adversities that life may bring. As in the case of transitional difficulties encountered by parents during their children's home education process, the parents were able to embrace these difficulties and achieve a balance between meeting the needs of the child with ASD, the needs of the family as a whole, and the needs of other family members.

Moreover, many parents/guardians, in their quest to cope with the situation where they find themselves responsible for teaching and educating their children at home, adopt a style of consulting and connecting with the teachers in school and special therapists. This is the adaptive coping method of seeking social support as highlighted by Lai and Oei (2014) in their studies. Going back to teachers and therapists to discuss their concerns about their child enlightens them and they are able to acquire additional learning and information on how to manage the home education process. This will ensure parents and teachers have an improved educational outcome for their children with ASD.

\section{Parent-School Partnership}

Family-school-community partnerships are a shared responsibility and reciprocal process whereby schools and other community agencies and organizations engage families in meaningful and culturally appropriate ways, and families take the initiative to actively support their children's development and learning. Schools and community organizations also make efforts to listen to parents, support them, and ensure that they have the tools to be active partners in their children's school experience (NCSSLE, 2021).

Parents are the first educators of their children and they continue to influence their children's learning and development during their school years and long afterwards. Schools bear the important responsibility of nurturing and teaching future generations, and families rely on schools to lay the educational groundwork for their children's future. That is the importance of parents and schools working together in a partnership. The Parent-School Partnership refers to the collaborative relationships and activities between parents or families and the school. According to the responses of the participants, Parent E stated, "I do a lot of things; I establish open communication with the SPED Teacher and ask how I should be working out with it. Second, even though my son is no longer connected with the occupational therapy center. I still continue to talk to the therapist and ask for advice on how we will cope with the struggle."Parent A also shared, "I still ask and consult the teacher about what to do." Parent D underpinned this with her statement, "We also ask and consult the teacher on what to do," and supported by Parent B, "By going back to therapy."

The new normal in education calls for a renewed collaboration between teachers and parents, who must work together in the best interest of students. This is consistent with the article by Perras (2021), which states that educators and parents generally agree that positive, supportive, and open relationships between home and school, parents and teachers, are desirable. Additionally, research has shown that parent engagement and successful parent-teacher partnerships result in improved educational outcomes for students. Parents and guardians are encouraged to collaborate with their children's school or classroom teachers to enable them to 
DOI: $\underline{10.51386 / 25815946 / \mathrm{ijsms}-\mathrm{v} 4 \mathrm{i} 4 \mathrm{p} 102}$

Volume: 4 Issue: 4

July to August 2021

https://www.ijjsmsjournal.org

establish a link to better educate their children at home. It is a shared responsibility based on mutual trust and respect. Partnerships with parents keep parents informed about their children's learning and development. This assures parents and teachers that their students will have a better educational experience.

\section{Special Journey}

The experience of having a child on the autism spectrum greatly affects the lives of most parents. Prior to the pandemic, parents' daily routines included doing housework, going to work, tending to family needs, and driving their children to school. With the unexpected emergency health crisis, parents have now taken on the role of educators, guiding their children through learning modules given by schools and online classes. According to the United Nations report, "the COVID-19 pandemic has created the largest disruption of education system in history, affecting nearly 1.6 billion learner in more than 190 country and all continents. Closures of schools and other learning spaces have impacted 94 percent of the world's student population, up to 99 percent in low and lower middle-income countries (UN, 2020). For the parents of children with special needs, particularly ASD, finding a solution to the "new normal" education is a positive way of focusing on the child instead of dwelling on the challenging situation. Filipino parents' unique approach to surviving this new learning modality has given them a fresh perspective. Parents have become hands-on and have direct involvement in educating their children and this has become an opportunity for them to monitor their children's progress. As imparted by Parent A,"I am able to fully attend to him and teach him regardless of how small or large his improvements are, which we regard as a great accomplishment. "Parent $\mathbf{H}$ joined this statement when she responded, "Because I really attended to him." Through it all, parents have learned to embrace the "new normal" in education, which makes them encounter rewarding and fulfilling experiences as they navigate through this special journey.

\section{Essential Learning Designs}

Staying at home and not attending school creates a uniquely stressful situation for children with special needs and their families. It is noted that the disruption can be particularly devastating to students with disabilities such as autism, who thrive on routine and regular schedules. Though structured home education is difficult in the transitional period, Cahapay (2020) noted that parents have collectively voiced out that any form of education transpiring within their homes is important to the development of their children.

Learning at home can be tailored to the needs of their children and family conditions. So, learning activities are more focused. This is supported by Feeney (2020), who reported that many parents of children with special needs are looking into home education as an alternative to education. Furthermore, he claims that home education is beneficial for children with autism and will provide them with the best learning environment possible. Narzisi (2020) added that home-based learning will maximize a child's potential early on, without having to adhere to the usual time standards set by schools. As in the case of children with autism, who work and learn at their own pace.

Home education provides for optimal learning (Cahapay, 2020). This could be the right time to learn about the essentials of life. Some people may think that children with special needs should not be given duties and responsibilities at home. UNESCO (2020) indicates that it is important to note that the duties you entrust to them and the work they take up can contribute to molding them and helping them develop identities of their own. As simple as keeping their things safe, secure and clean, and cleaning the dining tables after having dinner, can be assigned as responsible tasks. This would help them develop a sense of responsibility. Small roles could also be given in each of the tasks performed by the elderly, as this would increase the confidence level of the child and help in the formation of an identity. This is supported by the Theory of the Hierarchy of Needs of Abraham Maslow, which offers a framework for how humans can thrive. When basic needs are met, selfactualization occurs, according to the theory.The love, warmth, and care provided by parents has made children respond positively, hence, making both parents and children thrive and develop a sense of belongingness and a sense of being loved, therefore making the home education experience a special journey. 
DOI: $\underline{10.51386 / 25815946 / \mathrm{ijsms}-\mathrm{v} 4 \mathrm{i} 4 \mathrm{p} 102}$

According to the participants of the study, when asked, what made your involvement in your child's homeschooling a special journey? The parents gladly shared their experiences, such as their hands-on, learning, and rewarding experiences. As Parent G cited, "A special journey because I am able to give special time, special attention and special patience to my child. "Parent $\mathbf{D}$ also shared, "A special journey because, while we are teaching him, we are also learning to be more patient."The rewarding experiences of parents give them fulfillment and enrichment, as Parent $\mathbf{C}$ exclaimed, "It is a special journey because he makes me feel like a child whenever he laughs. All of his milestones, though slow, are unpredictable when shown, as if you're floating on a cloud nine. "Parent $\mathbf{H}$ corroborated this when she mentioned, "Even if it's a pandemic and he's doing homeschooling, he's making progress because I really attended to him. 'This is followed up by Parent B's response, "Because I can see his improvement and milestones." While Parent F declared, "The journey has never been tougher, but very rewarding with his milestones." Parents, as the primary educators during homeschooling, have an important role in the development of children with ASD to their full potential. Parents can take a holistic approach to home education, which means that education is not only focused on academics but also on all aspects of the child's personality, such as physical, mental, emotional, and social. That is why any learning design and concept that will evolve during the home education process is considered essential to the growth and development of the child. When parents consider all these aspects with the inclusion of a balanced and healthy home environment, the child's development and learning will be realized based on what the Behavioral and Developmental Theory discloses.

\section{CONCLUSIONS AND RECOMMENDATION}

\section{A. Conclusion}

From the foregoing findings, the following conclusions are derived:

1. The participation of the parent improves the performance of the child during homeschooling.

2. Parents become wiser and stronger to manage the challenges which are experienced by the parents during homeschooling.

3. A renewed Parent-School Partnership is deemed necessary for the learning continuity of children with ASD.

4. The various home learning routines required for a child's growth and development are referred to as essential learning designs.

5. The model crafted from the themes is helpful in improving homeschooling practices.

\section{B. Recommendations}

In the light of the findings and conclusions, the following recommendations were offered:

1. A colloquium scheme should be adopted and implemented by schools which may be characterized by the following features:

a. This will provide a greater understanding of the types of support and potential interventions needed by the parents or families of children with ASD.

b. Trained professionals, such as developmental pediatricians, therapists, psychologists, special education teachers, and parents, will be asked to share and exchange knowledge based on their areas of expertise and specialization. school.

c. The venue of the colloquium will be online using Zoom or Google Classroom or any platform of choice by the

d. The colloquium will be held once a month and will last for about 30-45 minutes each.

e. This will be spearheaded by the school principals and facilitated by the heads of the SPED Centers.

f. The secretariat consists of the school's guidance office, the marketing office and the SPED department to ensure the colloquium is organized and managed.

g. An online evaluation will be conducted after every colloquium in which suggestions and recommendations are documented, reviewed, and given action for further improvement and development of the colloquium.

2. Schools should create an active support group for the parents of children with ASD. This support system will serve as a channel and an opportunity for them to share their personal experiences and feelings, coping strategies and first-hand information on parenting and home educating their children with ASD.

3. To maintain the relationship between the parents and the school, teachers must have important information about the parents, such as who the parents are, what they do, and how they are coping during the home education process.

4. Schools should conduct an online survey for parents to assess and understand what type of support they need from the school. 


\section{DOI: $10.51386 / 25815946 / \mathrm{ijsms}-\mathrm{v} 4 \mathrm{i} 4 \mathrm{p} 102$}

5. Frequent and clear communication is the key to keeping parents engaged. Schools should regularly contact parents to provide updates on planned activities for the child and review any feedback or recommendations.

6. The school should appoint a parent representative to conduct correspondence and disseminate information to the parent group.

7. Schools should provide psychological counseling with the involvement of school guidance counselors during school meetings with parents. Many parents and families are undergoing stress and pressure due to the current pandemic crisis, thus needing psychological mentoring to support and sustain their mental health.

8. Schools should use virtual lessons to support parents and children's learning through self-guided lessons that allow parents to learn skills, activities and practices to support children's development.

9. Online workshops and multimedia tutorials should be designed to help parents become more comfortable with elearning tools.

10. Further research should be conducted to probe and delve into the challenges of parents of homeschooling children with ASD.

\section{ACKNOWLEDGMENT}

This research would not have been possible without the support of our dear Dean, Dr. Wilfred F. Cabauatan, Dr. Magdalena R. Japson, Dr. Augustina C. Dumaguin, andChristian Dem R. Haluber, for their precious time, insightful comments and recommendations as content validators. Their enthusiasm, knowledge, and exacting attention to detail have been an inspiration and kept our work on track from the first encounter. We were also grateful for the insightful comments offered by the anonymous peer reviewers and editorial board members of the IJSMS Journal. The unselfishness and creativity of one and all have improved this research in innumerable ways and saved us from many errors, those that inevitably remain our entire responsibility. Finally, we would like to express our gratitude to our families for their prayers, encouragement, and assistance in completing this study; God bless you all.

Ethics Approval: Researchers obtained a letter of permission from the necessary authorities to conduct this study, especially from the Saint Louis College Research Ethical Review.

Conflict of Interest: Researchers declared no conflicts of interest.

OrCIDiDs: 0000 - 0002 - 3444 - 4713.Google Scholars; Research Gate

\section{REFERENCES}

[1] Alcober, N. (2020). DepEd assures no face-to-face classes this year.https://tribune.net.ph/index.php/2020/05/28/deped-assures-noface-to-face-classes-this-year/.

[2] Bartlett, J.D., Griffin, J., \& Thomson, D. (2020). Resources for supporting children's emotional wellbeing during the COVID-19 pandemic Child Trends. https://www.childtrends.org/publications/resources-for-supporting-childrensemotional-well-being-duringthe-covid-19-pandemic/.

[3] Benson, P. R. (2010). Coping, distress, and well-being in mothers ofchildren with autism. Research in Autism Spectrum Disorders, $4(2), 217-228$.

[4] Berger, E.H. (2015). Parents as partners in education. Upper Saddle River, NJ: Pearson.

[5] Bonis, S. (2016). Stress and Parents of Children with Autism: A Review ofLiterature. Mental Health Nursing 37: 153-163.

[6] Borromeo, (2014). Number of people with Autism is increasing. https://beta.philstar.com/headlines/2014/04/10/1310840/number-ofpeople-with-autism-is-increasing/

[7] Cahapay, M. (2020). How Filipino parent's home educate their childrenwith autism duringCOVID-19 period. International Journal ofDevelopmental Disabilities. https//doi.org/10.1080/20473869 .2020.1780554.

[8] Capulso, L. (2020). Braving the K-12 Education in the Philippines Amidst the Covid-19 Pandemic.https://www.K12digest.com/bravingthe-k12-education-in-the-philippines-amidst-the-covid-19-pandemic/.

[9] Clifford, T., \&Minnes, P. (2013). Who participates in support groups for parents of children with autism spectrum disorders? The role ofbeliefs and coping style. Journal of Autism and Developmental Disorders, 43(1), 179-187. 


\section{DOI: $\underline{10.51386 / 25815946 / \mathrm{ijsms}-\mathrm{v} 4 \mathrm{i} 4 \mathrm{p} 102}$}

[10] Department of Education. Department of Education Order No. 32, s. (2020). https://www.deped.gov.ph>DO_s2020_032-1-1.

[11] Epstein, J.L. (2010). In School, family, and community partnerships: Your handbook for action. (3rd ed.). Corwin Press.

[12] Eshraghi, A. A., Li, C., Alessandri, M., Messinger, D. S., Eshraghi, R. S., Mittal, R., \&Armstrong, F. D. (2020). COVID-19: Overcoming the challenges faced by individuals with autism and their families. Lancet Psychiatry, 7(6), 481-483. https://doi:10.1016/S2215-0366(20)30197-8.

[13] Fadare, A.S., Adeniran, K.O. \& Fadare, C.M. (2021). A hermeneutical phenomenology of parenting children with autism spectrum disorder. Orapuh Journal, 2(1),e803.

[14] Falk, N.H., Norris, K., \& Quinn, M. (2014). The factors predicting stress, anxiety and depression in the parents of children with autism.

Autism Developmental Disorder. 2014 Dec;44(12):3185-203. https//doi.org/0.1007/s10803-014-2189-4.

[15] Feeney, P. T. (2020). Home-schooling children with special needs during COVID-19 quarantine. Parents speak candidly about the challenges and realizations. Tap into South Plainfield. htpps://www.tapinto.net/towns/south-plainfield/sections/board-ofeducationarticles/homeschooling-children-with-special-needs-during-covid-19.

[16] Hastings, R. P., Kovshoff, H., Brown, T., Ward, N. J., Espinosa, F. D., \& Remington, B. (2015). Coping strategies in mothers and fathers of preschool and school-age children with autism. Autism, 9(4), 377-391. https//doi.org/10.1177/1362361305056078.

[17] Hayes, S. A., \& Watson, S. L. (2013). The impact of parenting stress: A meta-analysis of studies comparing the experience of parenting

stress in parents of children with and without autism spectrum disorder. Journal of Autism and Developmental Disorders, 43 (3),629-642. https://doi.org/10.1007/s10803-0121604-y.

[18] Imray, P., Gazquez, D.\&Bond, L. (2010). A PMLD Curriculum for the $21^{\text {st }}$ Century. The SLD Experience, $58,11-17$.

[19] Ingersoll, B., \&Hambrick, D. Z. (2011). The Relationship between the Broader Autism Phenotype, Child Severity, and Stress and Depression in Parents of Children with Autism Spectrum Disorders. Research in Autism Spectrum Disorders, 5, $337-344$.

[20] Kidd, T. (2010). The experiences of mothers' home educating their children with autism spectrum disorder. https://. iier.org.au /iier20/kidd.pdf.

[21] Klein, R. (2020). Most teachers say they're comfortable going back to school, but only with strict safety measures. https://www.news.yahoo.com/coronavirus/aft-safety-poll-221802524.html.

[22] Lai, W. W., \&Oei, T. P. (2014). Coping in parents and caregivers of children with autism spectrum disorders (ASD): Review on Autism Developmental Disorder (2014) 1:207-224. https://link.springer.com/content/pdf/10.1007/s40489-014-0021-x.pdf.

[23] Ludlow, A., Skelly, C., \&Rohleder, P. (2012). Challenges Faced by Parents of Children Diagnosed with Autism Spectrum Disorder. Journal onHealth Psychology 17: 702-711.

[24] Moh, T. A., \&Magiati, I. (2012). Factors associated with parental stress and satisfaction during the process of diagnosis of children with autism spectrum disorders. Research in Autism Spectrum Disorders, 6(1), 293-303.

[25] Narzisi, A. (2020). Handle the Autism Spectrum Condition During Coronavirus (COVID-19) Stay At Home Period: Ten Tips for Helping Parents and Caregivers of Young Children. https://www.researchgate.net/publication/340366877.

[26] National Autistic Society. (2021). Meltdowns-a guide for all audiences. https://www.autism.org.uk/advice-and-guidance/topics /behaviour/meltdowns/all-audiences\#.

[27] National Centre On Safe Supportive Learning Environments. (2021). Family-School-Community Partnerships. https:// safesupportivelearning.ed.gov. /Training-technical-assistance/ education-level/early-learning/family-school-community-partnerships.

[28] National Council on Disability Affairs. (2020). Disability Laws. https://www.ncda.gov.ph/disability-laws/.

[29] Parnell, J. (2017). Six Tips for Home-schooling Your Child with Autism Spectrum Disorder. https://friendshipcircle.org/blog /2017/ 04/13/tips-for-homeschooling-your-child-with-autism-spectrum-disorder/.

[30] Perras, C. (2021). Effective Parent-Teacher Partnerships: Considerations for Educators. https://ldatschool.ca/effective-parent-teacherpartnerships/.

[31] Samadi, (2012). Genetic influences on the broad spectrum of autism: Study of proband-ascertained twins.http://onlinelibrary.wiley.com /doi/10.1002/ajmg.b.30740/full.

[32] Shourbagi, S. (2017). Parental involvement in inclusive classrooms for students with learning disabilities at Omani schools as perceived by teachers. https://www.alliedacademics.org/journal-of-psychology-and-cognition/. 


\section{DOI: $\underline{10.51386 / 25815946 / \mathrm{ijsms}-\mathrm{v} 4 \mathrm{i} 4 \mathrm{p} 102}$}

[33] Sun, X., \& Allison, C. (2010). A review of the prevalence of Autism SpectrumDisorders,4(2),156-167. https://dx.doi.org/10.1016/j.rasd.2009.10.003

[34] United Nations Educational, Scientific and Cultural Organization. (2020). Life in the Times of COVID-19: A Guide for Parents of Children with Disabilities. New Delhi. https://en.unesco.org/fieldoffice/.

[35] UNICEF. (2020). Leaving No Child behind during the Pandemic: Children with Disabilities and COVID-19. https://data.unicef.org/topic/child-disability/covid-19.https://mindtools.com/pages/article/newHTE_00.htm.

[36] What is Time Management? (2021). Working Smarter to Enhance Productivity.https://mindtools.com/pages/article/newHTE_00.htm.

[37] Whitbread, K. M., Bruder, M. B., Fleming, G., \& Park, H. J. (2017). Collaboration in Special Education: Parent-Professional Training. https://doi.org/10.1177/004005990703900401.

[38] W H O. (2020). WHO Director-General's Opening Remarks at the Media Briefing on COVID-19. https://www.who.int/dg/speeches/detail /who-directorgeneral-s-opening-remarks-at-the-media-briefing-on-covid-19-11-march-2020. 